\title{
Mechanical Properties and Formability of Ultrasonic Treated Twin Roll Casting Magnesium Alloy Sheet
}

\author{
Yu Kun, Xiong Hanqing, Dai Yilong, Teng Fei, Fan Sufeng, Qiao Xueyan, \\ Wen Li
}

State Key Laboratory of Powder Metallurgy, Central South University, Changsha 410083, China

\begin{abstract}
The effects of ultrasonic treatment on the microstructure and properties of twin roll casting $\mathrm{Mg}-2.45 \% \mathrm{Al}-0.92 \% \mathrm{Zn}-0.69 \% \mathrm{Ce}-0.21 \% \mathrm{Mn}$ alloy strip were studied. The results show that the ultrasonic treatment improves strength, elongation and limiting drawing ratio of the alloy strip. The highest limiting drawing ratio of the sheet is 2.16 at $250{ }^{\circ} \mathrm{C}$. The improvement of properties is attributed to the refinement of $\alpha$ - Mg grains and the modification of $\mathrm{Mg}_{17}(\mathrm{Al}, \mathrm{Zn})_{12}$ and $\mathrm{AlCeMn}$ phases by ultrasonic treatment during the twin roll casting process. The grain size of the twin roll casting strip is refined from 150 $\mu \mathrm{m}$ to less than $30 \mu \mathrm{m}$ with the ultrasonic treatment power of $800 \mathrm{~W}$, and the needle-like shape of the AlCeMn phase is modified to a globular shape; therefore, the mechanical properties and formability of the magnesium alloy sheet are improved.
\end{abstract}

Key words: magnesium alloy; grain refining; twin roll casting; ultrasonic vibration

Magnesium alloys have been used in the automotive and electronic industries because of their light mass and high specific strength ${ }^{[1]}$. In particular, the demand for light mass automobile construction has increased for petrol conservation ${ }^{[2]}$. Magnesium alloys are one of the suitable candidates to replace steel and aluminum for automotive sheet applications. However, the major barrier for the widespread application of magnesium alloy sheets in cars is their high manufacturing cost ${ }^{[3]}$. Because magnesium has a hexagonal close-packed crystal structure with limited workability and deformability at ambient temperature, the magnesium alloy slabs need to be reheated frequently for hot rolling. As a result, the magnesium alloy sheets from direct chill (DC) cast ingots are more expensive than steel and aluminum alloys ${ }^{[4,5]}$. It is known that twin roll casting (TRC) can produce magnesium alloy strips less than $6 \mathrm{~mm}$ in thickness compared to the conventional ingot casting magnesium slabs that have thicknesses of 100 300 $\mathrm{mm}^{[6,7]}$. The TRC process can save several production steps in the manufacturing of sheets compared to DC technology. However, the problems of TRC magnesium alloys include coarse columnar grains, large amounts of defects, such as edge cracks or surface voids, and the restriction to dilute alloys with a narrow freezing range ${ }^{[8]}$. Magnesium is generally alloyed with the addition of $3 \% \mathrm{Al}$ and $1 \% \mathrm{Zn}$ to obtain a wrought magnesium alloy with a narrow freezing range from 605 to $630{ }^{\circ} \mathrm{C}$, which is suitable for $\mathrm{TRC}^{[9]}$. A small amount of manganese can improve the corrosion resistance of $\mathrm{Mg}-\mathrm{Al}-\mathrm{Zn}$ system alloy ${ }^{[10]}$. The addition of cerium in the $\mathrm{Mg}-\mathrm{Al}-\mathrm{Zn}$ alloy increases oxidation resistance of molten magnesium liquid during the TRC process and refines the casting grains ${ }^{[11]}$. Therefore, in the present paper, the $\mathrm{Mg}-3 \% \mathrm{Al}-1 \% \mathrm{Zn}-0.8 \% \mathrm{Ce}-0.3 \%$ (wt $\%$ ) $\mathrm{Mn}$ alloy was designed to produce sheets by TRC technology. There are few reports about the technology applied in the TRC process to fabricate magnesium alloy strips. Thus, ultrasonic treatment (UST) of the molten alloy was performed to improve the quality of the experimental magnesium alloy during the TRC process ${ }^{[12]}$. The comparison of the microstructure and mechanical properties of TRC Mg-Al$\mathrm{Zn}-\mathrm{Ce}-\mathrm{Mn}$ alloy with or without UST in different conditions

Received date: March 15, 2016

Foundation item: Open Fund of the State Key Laboratory of Powder Metallurgy

Corresponding author: Yu Kun, Ph. D., Professor, School of Materials Science and Engineering, Central South University, Changsha 410083, P. R. China, Tel: 0086-731-88879341, E-mail: yukun2010@csu.edu.cn 
was provided to study the effects of UST and to develop new technology to fabricate high quality TRC magnesium alloy strips.

\section{Experiment}

A lab-scale version of a twin roll caster machine with a pair of steel rollers of $400 \mathrm{~mm}$ in diameter and $500 \mathrm{~mm}$ in width was used in the experiment. The rotation speed and gap of the rollers could be adjusted according to the experimental conditions. The nominal composition of the experimental alloy was Mg-2.45\%Al-0.92\%Zn-0.69\%Ce- $0.21 \% \mathrm{Mn}$ (wt $\%$ ). The alloy was melted at $660 \sim 680{ }^{\circ} \mathrm{C}$ and transferred into a preheated header box with a size of $260 \mathrm{~mm} \times 200 \mathrm{~mm} \times 80 \mathrm{~mm}$, where the liquid flowed into the roll casting zone. The setting width of the TRC experimental alloy was $260 \mathrm{~mm}$, and the thickness was $4.0 \mathrm{~mm}$. The contact length between the rollers and molten metal was $45 \sim 46 \mathrm{~mm}$. The roll casting speeds were varied from 2.5 to $2.8 \mathrm{~m} / \mathrm{min}$. The molten alloy was shielded by the $\mathrm{CO}_{2}+0.5 \mathrm{vol} \% \mathrm{SF}_{6}$ mixture gas during the TRC procedure.

In the experiment, ultrasound was performed on the molten experimental alloy in the header box during the whole twin roll casting process. The ultrasonic oscillation device used in the TRC consisted of an acoustic generator and a transducer with a stainless steel horn. The horn was immersed about $10 \sim 15 \mathrm{~mm}$ deep in the molten alloy. The fixed frequency of ultrasound was $20 \mathrm{kHz} \pm 200 \mathrm{~Hz}$. The ultrasonic powers of 400 $\mathrm{W}$ and $800 \mathrm{~W}$ were introduced through the ultrasonic generator in the molten alloy liquid with a temperature of $660 \sim 680{ }^{\circ} \mathrm{C}$ to evaluate the effects of UST.

The tensile test was performed to evaluate mechanical properties of the TRC experimental alloy in as-cast, hot rolling and annealing conditions. All experimental specimens were machined from the TRC strips with or without ultrasonic treatment. The TRC alloy strip without the UST was prepared as a control specimen. Three types of tensile samples were machined from the TRC strips parallel to the casting direction (CD) and the transverse direction (TD) and at an intermediate $\left(45^{\circ}\right)$ orientation (as shown in Fig. 1). Three measurements per sample were performed, and the average values were used to describe the tensile properties. The tensile test was performed on an Instron 8032 mechanical testing machine at ambient

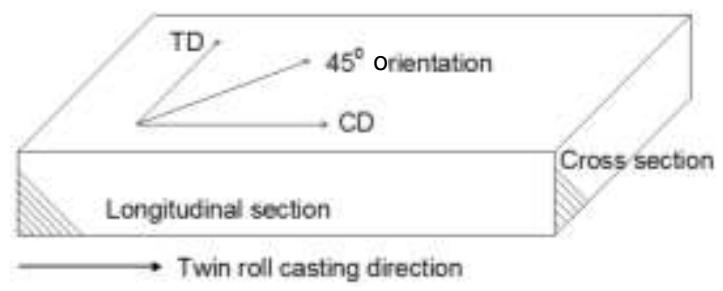

Fig.1 Schematic diagram of specimens machined from the twin roll casting strip temperature in accordance with ASTM standard B557M-94.

The TRC experimental alloy strips were homogenized at $450{ }^{\circ} \mathrm{C}$ for $12 \mathrm{~h}$ and then hot rolled at $400 \sim 450{ }^{\circ} \mathrm{C}$ from approximately $3.6 \sim 4 \mathrm{~mm}$ to $1.2 \sim 1.3 \mathrm{~mm}$ with three rolling passes. Each rolling reduction was about $25 \%, 33 \%$ and $35 \%$. After hot rolling, the rolled alloy sheet was annealed at $400{ }^{\circ} \mathrm{C}$ for $1 \mathrm{~h}$ and cooled in the furnace. The deep drawing ability test was performed on a HILLE universal sheet metal testing machine to examine the forming characteristics of the magnesium alloy sheets produced by the TRC strip.

The microstructures of the experimental alloy in different conditions were examined by a Polyvar-MET optical microscope $(\mathrm{OM})$ with a digital software to calculate the average grain size, a JSM-5600Lv scanning electron microscope (SEM) with energy-dispersive X-ray spectroscopy (EDX) and a Tecnai $\mathrm{G}^{2} 20$ transmission electron microscope (TEM). The samples for optical observation were polished by emery paper and etched in a $0.5 \mathrm{vol} \%$ nitric acid-ethanol solution. Samples examined by TEM were electro-polished by a twin-jet electro-polishing facility in a mixture of $3 \% \mathrm{HNO}_{3}$ and $97 \%$ ethanol at a temperature of $-15 \sim-25{ }^{\circ} \mathrm{C}$.

\section{Results and Discussion}

\subsection{Microstructures and properties of TRC Mg-Al-Zn- Ce-Mn alloy strip in the as-cast state}

Fig.2 shows the microstructures of TRC experimental magnesium alloy strip without UST and with different applied UST power levels. The microstructure of TRC alloy without UST exhibits a typical dendrite of primary $\alpha-\mathrm{Mg}$ phase on the cross section of the strip. Although the TRC magnesium alloy generally obtains refined as-cast grains compared with the conventional DC ingots, the columnar dendritic structure is predominant over the equiaxed grain structure. As shown in Fig.2a, the dendrites of $\alpha-\mathrm{Mg}$ in the TRC alloy strip are coarse, and the grain size is over $150 \mu \mathrm{m}$. Normally, the cast strip is reduced by about $10 \%$ during the TRC process. The microstructure of the TRC strip on the longitudinal section along the casting direction shows that the dendrites deform and the grain sizes are heterogeneous after the continuous roll casting process (Fig.2b). The UST has a significant effect on the refinement of the $\alpha-\mathrm{Mg}$ phase dendrites. As shown in Fig.2c, with an ultrasonic power of $400 \mathrm{~W}$, about half of the amount of dendritic primary $\alpha-\mathrm{Mg}$ phases change to the spherical shape. The size of the dendrite grain drops to less than $100 \mu \mathrm{m}$. The grains on the longitudinal section also show heterogeneous morphology (Fig.2d). Increasing the UST power would result in less dendritic branches and shorter arms. With a high UST power of $800 \mathrm{~W}$, the dendritic grains change to uniform spherical grains with a size less than $30 \mu \mathrm{m}$ (Fig.2e). In particular, the grain deformation parallel to the roll casting direction is homogeneous on the longitudinal section (Fig.2f). 


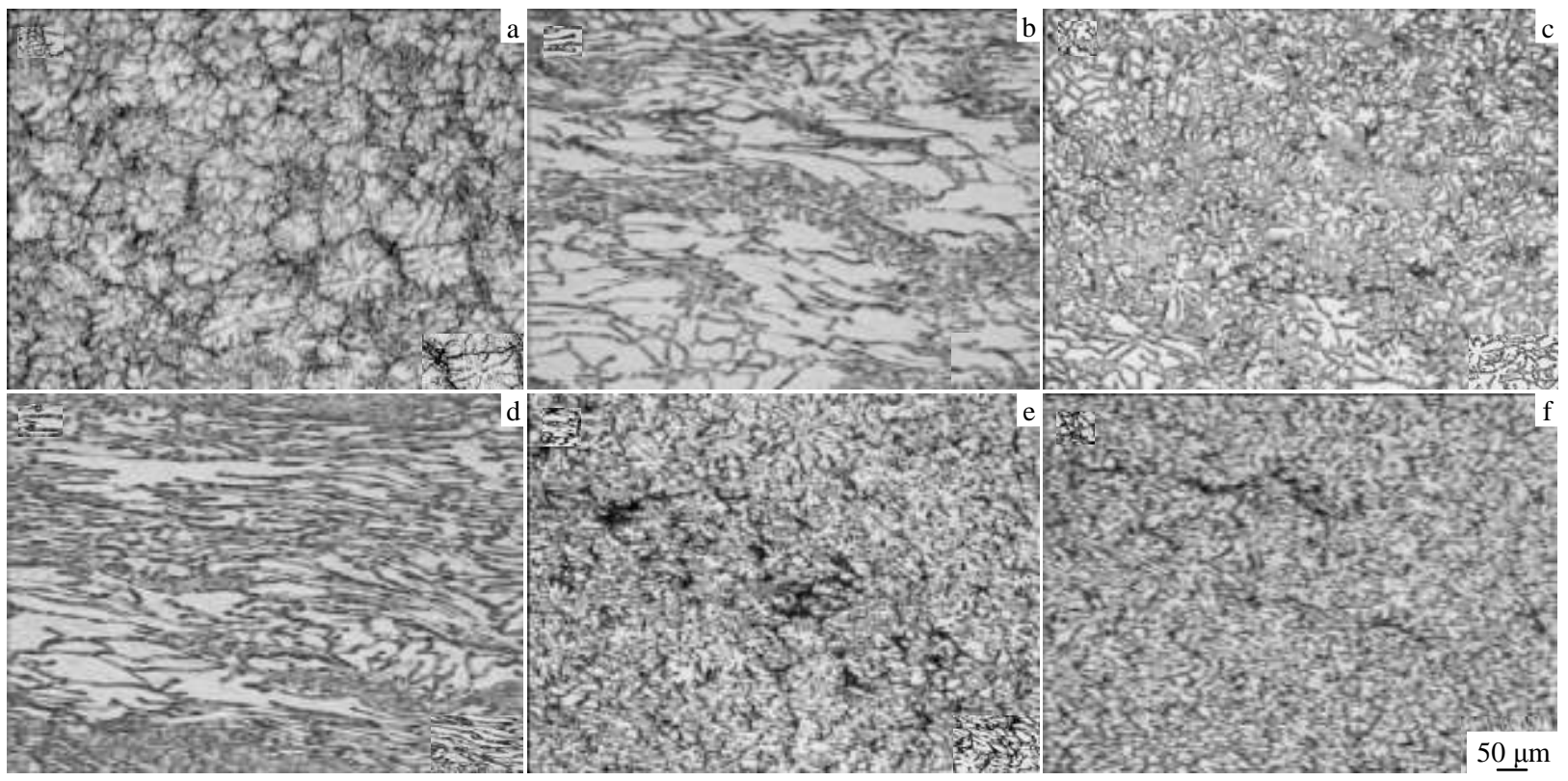

Fig.2 Optical micrographs of twin roll casting Mg-Al-Zn-Ce-Mn strip: (a) without ultrasonic treatment (on the cross section); (b) without ultrasonic treatment (on the longitudinal section); (c) with ultrasonic treatment power of $400 \mathrm{~W}$ (on the cross section); (d) with ultrasonic treatment power of $400 \mathrm{~W}$ (on the longitudinal section); (e) with ultrasonic treatment power of $800 \mathrm{~W}$ (on the cross section); (f) with ultrasonic treatment power of $800 \mathrm{~W}$ (on the longitudinal section)

Fig.3 presents the photographs of the casting quality of the TRC strip with or without UST. Two kinds of typical defects are observed on the surface of the TRC magnesium alloy strip (Fig.3a): small cracks with some voids on the surface (Fig.3b) and edge defects (Fig.3c). The SEM observation and the EDX identification of the intermetallic phases near the defects are shown in Fig.3d. The micro-cracks are generated near the intermetallic phase with the elements of $\mathrm{Al}, \mathrm{Ce}$ and $\mathrm{Mn}$. Generally, there are two typical intermetallics that could be detected in the TRC Mg-3\%Al-1\%Zn-0.8\%Ce-0.3\%Mn alloy. The $\operatorname{Mg}_{17}(\mathrm{Al}, \mathrm{Zn})_{12}$ phase has a relatively spherical shape, and the AlCeMn phase has a needle-like shape (Fig.3e). A minor content of cerium could improve the oxidation resistance and retard the inflammation of molten magnesium effectively. The cerium is helpful to protect the magnesium alloy melt during solidification of the TRC.

Furthermore, both cerium and manganese added to the $\mathrm{Mg}-\mathrm{Al}-\mathrm{Zn}$ system alloy could react with the impure elements, such as iron, copper or nickel in the molten state ${ }^{[11,12]}$. Usually, the addition of these two elements is enough to eliminate impurities from the molten $\mathrm{Mg}-\mathrm{Al}-\mathrm{Zn}$ alloy. However, the surplus of cerium and manganese also reacts with aluminum to form a needle-like intermetallic phase, which influences the deformation ability of the TRC strip during the roll casting process. The high hardness and the angular needle-like shape of the AlCeMn phase cause a great mismatch between it and the magnesium matrix, thus leading to the cracks formed near the AlCeMn phase during the TRC solidification process. With the
UST on the TRC Mg-Al-Zn-Ce-Mn alloy molten, the morphology of the intermetallic AlCeMn phase has a remarkable modification of shape and a refinement of size. Fig.3f shows that the needle-like AlCeMn phase transforms to globular and finer particles with no micro-cracks nearby under a UST power of $800 \mathrm{~W}$. Such a modification of the intermetallic AlCeMn by the UST is beneficial to improve the formability of the TRC magnesium alloy strip during TRC. As a result, the surface quality of the TRC Mg-Al-Zn-Ce-Mn alloy with a UST of $800 \mathrm{~W}$ clearly improved, as shown in Fig. $3 \mathrm{~g}$.

The tensile tests on TRC Mg-Al-Zn-Ce-Mn alloy with or without UST were conducted to study the connection between the mechanical properties with the microstructure. Fig.4 shows the effects of UST power on the yield strength, ultimate strength and elongation of TRC Mg-Al-Zn-Ce-Mn alloy along different directions. The TRC Mg-Al-Zn-Ce-Mn alloy strip obtains the acceptable anisotropic mechanical properties. The yield and ultimate strengths of the CD samples are higher than those of samples parallel to $45^{\circ}$ orientation and TD samples. The highest elongation value is acquired by the sample parallel to $45^{\circ}$ orientation, and the elongations of CD samples are higher than those of the TD samples. The mechanical properties increase with the enhancement of the UST power from 400 to $800 \mathrm{~W}$. The yield strength of TRC Mg-Al-Zn-Ce-Mn alloy strip with the UST $800 \mathrm{~W}$ is approximately by $40 \%$ higher than that of TRC alloy without UST. The elongation of TRC alloy with UST is almost double that without UST. The main reason for the improvement of the mechanical properties of TRC 

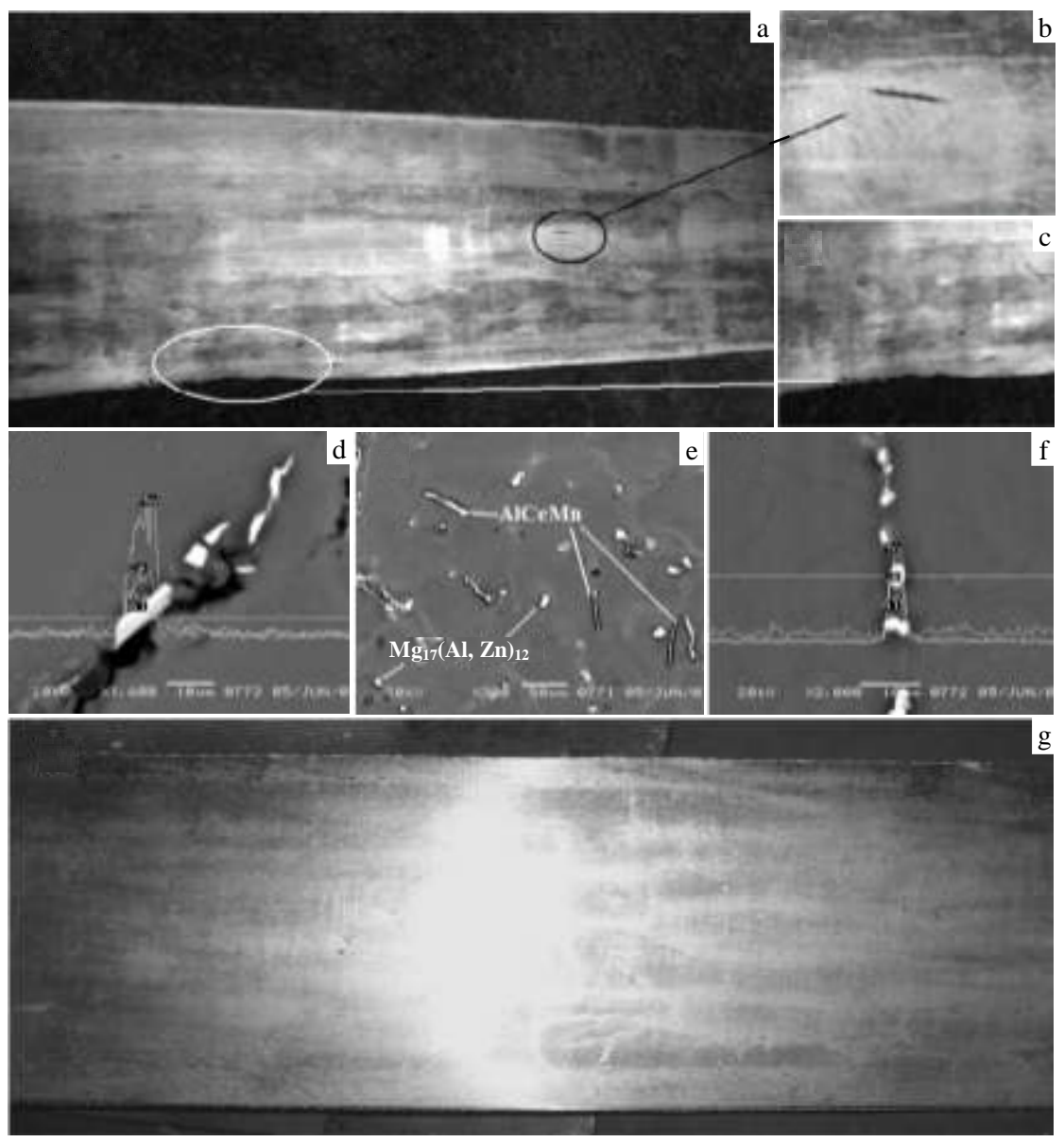

Fig.3 Casting quality of the twin roll casting Mg-Al-Zn-Ce-Mn strip: (a) surface condition of twin roll casting alloy strip without ultrasonic treatment; (b) small crack on the surface of twin roll casting alloy strip without ultrasonic treatment; (c) edge defect of twin roll casting alloy strip without ultrasonic treatment; (d) micro-crack near the intermetallic AlCeMn phase; (e) morphology and identification of the $\operatorname{Mg}_{17}(\mathrm{Al}, \mathrm{Zn})_{12}$ phase and AlCeMn phase; (f) modification of the AlCeMn phase by ultrasonic treatment; $(\mathrm{g})$ surface condition of the twin roll casting alloy strip with ultrasonic treatment
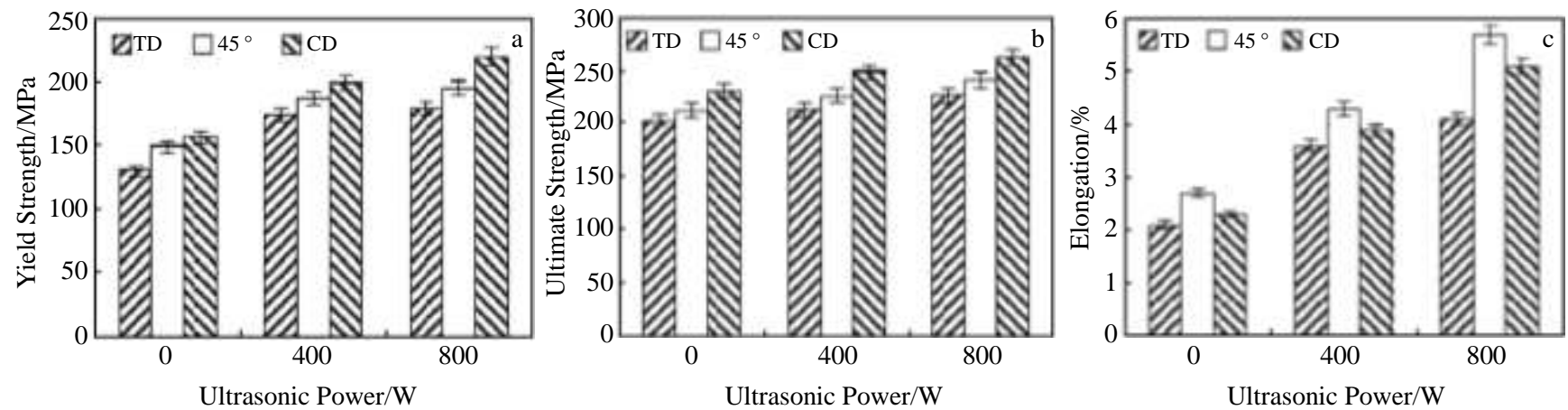

Fig.4 Tensile properties of twin-roll casting Mg-Al-Zn-Ce-Mn strips with different ultrasonic powers and along different directions: (a) yield strength, (b) ultimate strength, and (c) elongation

$\mathrm{Mg}-\mathrm{Al}-\mathrm{Zn}-\mathrm{Ce}-\mathrm{Mn}$ alloy with UST is the more uniform and finer microstructures of the alloy.

\subsection{Plastic formability of the annealed TRC Mg-Al-Zn- Ce-Mn alloy}

After the TRC magnesium strips were hot rolled with a total reduction of approximately $70 \%$ and annealed at $400{ }^{\circ} \mathrm{C}$ for $1 \mathrm{~h}$, a warm deep drawing test was performed to examine the forming characteristics of the TRC Mg-Al-Zn-Ce-Mn alloy sheets with or without UST. The forming conditions and the dimensions of the deep drawing tools are described in Table 1. 
During the deep drawing test, four forming temperatures were applied, ranging from 150 to $300{ }^{\circ} \mathrm{C}$. A fixed drawing speed of $40 \mathrm{~mm} / \mathrm{min}$ was chosen in the test. The calculated limiting drawing ratio (LDR) values at different temperatures in the test are shown in Fig.5. The results suggest that the wrought $\mathrm{Mg}-\mathrm{Al}-\mathrm{Zn}-\mathrm{Ce}-\mathrm{Mn}$ alloy sheets that are hot rolled after the TRC process have a plastic formability equivalent to that of the sheets manufactured by the conventional DC casting slabs (the approximate LDR value is 2.0 at $200{ }^{\circ} \mathrm{C}$ ). The appropriate temperature for the warm deep drawing of the TRC $\mathrm{Mg}-\mathrm{Al}-\mathrm{Zn}-\mathrm{Ce}-\mathrm{Mn}$ alloy sheets is $250{ }^{\circ} \mathrm{C}$. The ultrasonically treated TRC Mg-Al-Zn-Ce-Mn alloy obtains higher LDR values than the sheets without UST at different temperatures. The

Table 1 Dimensions of deep drawing tool and forming conditions

\begin{tabular}{cc}
\hline Parameter & Value \\
\hline Punch diameter $/ \mathrm{mm}$ & 50 \\
Die diameter $/ \mathrm{mm}$ & 53.5 \\
Drawing speed $/ \mathrm{mm} \cdot \mathrm{min}^{-1}$ & 40 \\
Blank holding force $/ \mathrm{kN}$ & 3 \\
Forming temperature $/{ }^{\circ} \mathrm{C}$ & $150,200,250,300$ \\
Lubricant & $\mathrm{Mo}_{2} \mathrm{~S}$ powder \\
\hline
\end{tabular}

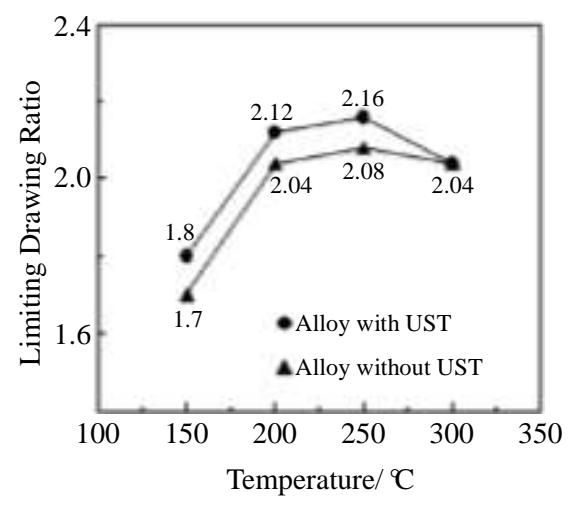

Fig.5 Relation between the limiting drawing ratio and temperatures of Mg-Al-Zn-Ce-Mn alloy sheets increase of plastic formability is mainly due to the refinement of the grains and intermetallics by the UST.

\section{Conclusions}

1) The UST improves the strength, elongation and LDR of TRC Mg-Al-Zn-Ce-Mn alloy. The improvement of the properties is due to the refinement of $\alpha-\mathrm{Mg}$ grains and the modification of the intermetallic AlCeMn phase by UST. During the TRC process, the grain size is refined from $150 \mu \mathrm{m}$ to less than $30 \mu \mathrm{m}$ with a UST power of $800 \mathrm{~W}$, and the needle-like AlCeMn phase is modified to a globular shape.

2) The TRC Mg-Al-Zn-Ce-Mn alloy sheet could be formed into a cup shape by deep drawing. The highest limiting drawing ratio of the sheet is 2.16 at $250{ }^{\circ} \mathrm{C}$.

\section{References}

1 Mordike B L, Ebert T. Mater Sci Eng A[J], 2001, 302(1): 37

2 Easton M, Beer A, Barnett M et al. JOM[J], 2008, 60(11): 57

3 Bettles C J, Gibson M A. JOM[J], 2005, 57: 46

4 Watarai H. Science \& Technology Trends[J], 2006, 18: 84

5 Ding P D, Pan F S, Jiang B et al. Trans Nonferrous Met Soc China[J], 2008, 18(S1): 7

6 Park S S, Park W J, Kim C H et al. JOM[J], 2009, 61: 14

7 Watari H, Haga T, Paisern R et al. Key Engineering Materials[J], 2007, 345-346: 165

8 Haga T, Watari H, Kumai S. J Achievements in Mater \& Manuf $\operatorname{Eng}[\mathrm{J}], 2006,15(1-2): 186$

9 Kaya A A, Duygulu O, Ucuncuoglu S et al. Trans Nonferrous Met Soc China[J], 2008, 18(S1): 185

10 Yu K, Li W X, Wang R C et al. Trans Nonferrous Met Soc China[J], 2007, 17(S1): 405

11 Qian M, Ramirez A, Das A et al. J Crystal Growth[J], 2010, 312(15): 2267

12 Yu K, Li W X, Zhao J et al. Scripta Materialia[J], 2003, 48(9): 1319

\title{
超声波作用下双辊铸轧镁合金板带材的力学性能和成形能力
}

\author{
余 琨, 熊汉青, 戴翌龙, 滕 飞, 范素峰, 乔雪岩, 文 利 \\ (中南大学 粉末冶金国家重点实验室, 湖南 长沙 410083)
}

\begin{abstract}
摘 要: 研究了超声波对双辊铸轧的 Mg-3\%Al-1\% Zn- $0.8 \% \mathrm{Ce}-0.3 \% \mathrm{Mn}$ (质量分数) 合金板带材组织和性能的影响。结果表明: 超声波 辅助镁合金的铸轧可以提高镁合金带材的强度、延伸率和极限深拉比值，在 $250{ }^{\circ} \mathrm{C}$ 镁合金带材的极限深拉比值可以达到 2.16 。这些镁合 金力学性能和成形能力的提升是由于超声波铸轧过程中, 超声波可以细化镁基体的晶粒尺寸, 并同时对合金中的 $\mathrm{Mg}_{17}(\mathrm{Al}, \mathrm{Zn})_{12}$ 和 $\mathrm{AlCeMn}$ 相起到变质作用。当超声波强度达到 $800 \mathrm{~W}$ 时, 镁基体的晶粒尺寸可以从 $150 \mu \mathrm{m}$ 细化到 $30 \mu \mathrm{m}$, 而且针状的 $\mathrm{AlCeMn}$ 相可以被变质成 球状, 从而提高了镁合金的力学性能和成形能力。
\end{abstract}

关键词：镁合金; 晶粒细化; 双辊铸轧; 超声波处理

作者简介: 余 琨, 男, 1974 年生, 博士, 教授, 中南大学材料科学与工程学院, 湖南 长沙 410083, 电话: 0731-88879341, E-mail: yukun2010@csu.edu.cn 